\title{
Translation of Narrative Prose From the Perspective of Eco-translatology —A Case Study of the English Version of Recalling Dashan
}

\author{
HU Yike, ZHANG Le \\ University of Shanghai for Science and Technology, Shanghai, China
}

\begin{abstract}
This paper selects Professor Hu Gengshen's eco-translatology as the theoretical guidance to explore how linguistic-dimensional transformation, cultural-dimensional transformation, and communicative-dimensional transformation are realized in the English version of Recalling Dashan. As narrative prose, Recalling Dashan records the friendship between Xi Jinping and Jia Dashan who is a local writer from Hebei Province. The words and sentences in this essay are full of sincerity and genuine. The translation of narrative prose is a difficult part of literary translation. Eco-translatology can be interpreted as translation studies from the perspective of ecology or an ecological approach to translation studies. As an interdisciplinary theory of ecology and translatology, eco-translatology has opened a new perspective in translation research. The translator solves the problems in translation with the three-dimensional transformation method based on the eco-translatology theory; the higher degree of three-dimensional integration may guarantee better translation quality. The English version of Recalling Dashan is chosen as the research object of this paper, which not only plays a guiding role for the translation of texts enjoying the same types, but also provides some references for the application and research of eco-translatology.
\end{abstract}

Keywords: eco-translatology, three-dimensional transformation, narrative prose

\section{Introduction}

Eco-translatology theory was proposed by Hu Gengshen in 2004 combing ecology with translation study. As an interdisciplinary theory of ecology and translatology, eco-translatology has opened a new perspective in translation research. Three-dimensional transformation is the translation method in eco-translatology, including linguistic, cultural, and communicative dimensional transformations. Three-dimensional transformation requires the translators to attach great importance to the language forms, and the realization of the bilingual communicative intentions.

It is rare to see the English version of Recalling Dashan. As narrative prose, we know that the translation of this type of essay is a difficult part of literary translation. Under the guidance of the three-dimensional adaptation and selection theory of eco-translatology, this paper discusses its translation strategies in linguistic dimension, cultural dimension, and communicative dimension with specific translation examples. The paper is

HU Yike, Master, postgraduate student, College of Foreign Languages, University of Shanghai for Science and Technology, Shanghai, China.

ZHANG Le, Doctor, associated professor, College of Foreign Languages, University of Shanghai for Science and Technology, Shanghai, China. 
composed of four chapters. Chapter one provides a brief introduction to the paper. Chapter two elaborates on the theoretical support of this paper. Chapter three focuses on the analyses of the cases with research values from the perspective of three-dimensional transformation. Chapter four is the conclusion mainly about the translator's gains and suggestions for further improvements from the translation.

\section{Literature Review}

Eco-translatology is guided by the basic principles and thoughts of Darwin's adaptation/selection theory, with the theme concept of "translation is adaptation and selection" as the keynote and the translation concept of translators as the center as the core (Hu, 2008a). In the "Interpretation of Eco-translatology", Hu Gensheng points out that eco-translatology is a kind of metaphor as well as a kind of real reference. The metaphor refers to the holistic study of translation ecology by analogy with natural environment ecology. Reality refers to the study on the relationship between translators and the translation ecological environment, especially the study on the survival situation and ability development of translators in translation ecology ( $\mathrm{Hu}, 2004)$. Translator-centered theory, adaptation and selection, and translation eco-environment are the three core concepts of eco-translatology $(\mathrm{Hu}, 2008 \mathrm{~b})$. This theory requires the translation process to have subjective initiative. The choice between the original text and the translator belongs to the first stage, in which the translator is passively selected. The translator and the translation belong to the second stage, in which the translator needs to exert subjective initiative and actively choose and manipulate the translation.

Eco-translatology's translation method is three-dimensional transformation based on the basic theory of eco-translatology $(\mathrm{Hu}, 2011)$. It is relatively focused on linguistic, cultural, and communicative dimensional transformation, which requires translators to pay attention to the language forms, the transmission and interpretation of cultural connotation of source and target languages, and the realization of bilingual communication intention. The higher degree of holistic adaptation and adaptive selection, the higher degree of holistic adaptation and selection will be realized.

Narrative prose is mainly used to express the author's subjective emotions. Different from novels, narrative prose mainly writes about real people and events, and the essay itself has no result, no discussion part, but has a clear structure. The reason why it is called narrative prose is that it has two elements: description and perception, both of which are indispensable. One type of narrative prose mainly writes about people and events. The narration and description of people and things in this kind of prose are more specific and prominent. It also has the characteristic of lyric scrapes and is full of those emotions between the lines. The target lyric should not only be faithful to the source but also be as beautiful as it is in a sense, sound, and form (Xu, 2006). Narrative prose focuses on reflecting the essence of things in the process of describing the development and change of characters and events, including time, place, characters, events, and other factors. This essay pays particular stress to characters. It often grasps the character traits to make a rough outline and pays more attention to the character's basic temperament, personality, and spiritual outlook.

\section{Interpretation of Chinese-English Translation From the Perspective of Three-Dimensional Translation Theory}

Eco-translatology is based on Chesterman's four complementary and overlapping approaches to translation studies: text-based translation studies, cognitive-based translation studies, sociology-based translation studies, and culture-based translation studies (Chesterman, 2005). The Chinese model of thinking is 
entirely different from westerners'. The holistic model of thinking is typical of Chinese, while westerners have the analytical mode of thinking (Lian, 2010). This has resulted in a huge difference in the way that the two languages express ideas and emotions. In the process of translation, the overall eco-environment of translation should be taken into full consideration. That is to say, vocabulary, sentence, and grammar should be adjusted accordingly, which mainly focuses on the dimension of language, culture, and communication.

\section{Linguistic Dimension}

The adaptive transformation of linguistic dimension refers to the translator's adaptive transformation of language form in the process of translation. The transformation is carried out in different aspects and at different levels. Hypotactic languages are concerned about the integrity of the sentence structure; Chinese, on the other hand, is a paratactic language with concise language forms and many sentences without the subject. In the process of translation, the translator should adjust the sentence structure and improve the content of the sentence by himself.

Example 1: 一个春寒料峭的傍晚, 我在工作人员陪同下来到大山居住的小屋, 相互问候之后, 便开 始了漫无边际的闲聊……

Translation: On a chilly spring evening, accompanied by workers, I went to the house where Dashan lived. After greeting, we began to chat...

Analysis: The phrase “春寒料峭” can immediately express the weather condition at night. We should select appropriate and concise words to make the translation vivid.

Example 2: 临别时，他还拉着我的手久久不愿放开: “近平，虽说我们是初次见面，但神交已久啊！ 以后有工夫，多来我这儿坐坐”。

Translation: When parting, he still took my hand for a long time reluctant to let go: "Jinping, we met for the first time, however, we had a long time for a spiritual exchange! Come and see me as often as you can".

Analysis: The word “神交” in Chinese is a word that needs to be understood by insight. It must be interpreted appropriately when it is translated into English. However, it should be as faithful as possible to the original text. The English version also needs to maintain the tone of oral English in the process of translation, as well as the proper wording and sentence style.

Example 3: 为了不影响机关门卫的休息, 我们常常叠罗汉似的, 一人先蹲下, 另一人站上肩头, 悄 悄地从大铁门上翻过。

Translation: In order not to disturb the guard, one of us squatted first, the other standing on his shoulder, quietly over the iron gate, like a pyramid.

Analysis: The word “叠罗汉” is an image expression in Chinese. In order to help readers understand, we need to find a similar description to clarify the explanation.

\section{Cultural Dimension}

We must place particular emphasis on the transfer and interpretation of two languages' cultural connotation in the process of translation from the perspective of adaptive transformation of cultural dimension. The transformation involves the differences in nature and content between the source language culture and the target language culture. And we try to avoid the distortion of the source text from the perspective of the target language culture. The translator should focus on the adaptation of the whole cultural system of the target language while transforming the source language. Language is the life product of social culture, so we need to pay attention to the transmission of bilingual cultural connotation in translation. 
Example 4: 1982年早春, 我要求离开中直机关到基层锻炼, 被组织分配到正定任县委副书记。

Translation: In the early spring of 1982, I asked to leave the central committee to exercise myself at the grassroots level and was assigned to Zhengding as the deputy secretary of the county party committee.

Analysis: Due to the different political systems and special abbreviations in Chinese, it is necessary to fully explain people's name in the translation process so that the target language readers can understand the specific meanings of some proper nouns.

Example 5: 常山影剧院、新华书店、电影院等文化设施的兴建和修复, 隆兴寺大悲阁、天宁寺凌霄 塔、开元寺钟楼、临济寺澄灵塔、广惠寺华塔、县文庙大成殿的修复, 无不浸透着他辛劳奔走的汗水。

Translation: Construction and restoration of cultural facilities not only including Changshan Theater, Xinhua Bookstore, cinemas, and other cultural facilities, Da Bei Pavilion of Longxing Temple, Lingxiao Tower of Tianning Temple, Bell Tower of Kaiyuan Temple, Linji Temple Chengling Tower, Flowery Pagoda, and Xianwen Temple Dacheng hall are also included. The repairs were soaked in his sweat.

Analysis: China has many ancient pagodas, bell towers, and temples. When these proper names are translated into English, Chinese Pinyin and literal translation are normally used, unless the facilities have specific English name.

Example 6: 他利用与基层民众水乳交融的关系, 充分调动各种历史和文化知识, 以谈谐幽默的语调, 合情入理的分析, 乐观豁达的情绪, 去劝说人们、影响人们, 主动地做一些疏导和化解矛盾的工作。

Translation: He took advantage of the harmonious relationship with the grassroots, fully mobilized a variety of historical and cultural knowledge, humorous tone, reasonable analysis, optimistic and open-minded mood, to persuade people, influence people, take the initiative to do some work to ease, and resolve conflicts.

Analysis: In Chinese, the word “水乳交融” refers to the fusion of water and milk. In this article, it refers to the close relationship between Jia Dashan and the grassroots people. The translation only needs to express this close relationship. Even without detailed explanation, the target language reader can also quickly understand.

\section{Communicative Dimension}

In translation, the translator should pay attention to the adaptive change of two languages communicative intention. The transformation requires the translator to concentrate on the communicative level. We should focus on whether the communicative intention in the original text can be reflected in the translated text. In addition to the transformation of linguistic information and the transfer of cultural connotation, the purpose of communication is that readers of the target language can comprehend the real emotion expressed by the author of the original text through reading the translation and resonating with the readers of the original text in terms of thoughts. Therefore, the communicative purpose is also an important criterion to measure the quality of translation.

Example 7: 我提出再和他照张合影, 他笑着说: “我已瘦成这样, 不像个人样儿了, 叫人看见怪吓 人的呀!”

Translation: I suggested taking another picture with him, he smiled and said, "It's too scary to see me that I'm too skinny and not like a normal people!"

Analysis: In Chinese, “不像个人样儿了” is used to indicate that a person or a thing is not suitable for a certain occasion. In the process of translation, we can only paraphrase this sentence. That is to explain the meaning of this sentence to avoid ambiguity. 
Example 8: 他常向与我联系较多的同志探询, 密切关注着我的工作情况和动向, 我也经常向到南方 出差的正定的同志询问他的身体、工作和创作状况。

Translation: He often inquires about my information with my colleagues that I frequently contact, pay close attention to my work and trends. I also ask his workmate about his health, work and create situations that often have a business trip to the south.

Analysis: The word “同志” is rarely used in western countries. In the translation process, the word “同志” is replaced by "colleague" and "working partner", so as to achieve the communicative purpose.

\section{Conclusion}

From the perspective of eco-translatology, this paper uses three-dimensional translation theory to interpret Chinese-English translation, and illustrate different translation strategies and approaches for different dimensions. It not only requires the translator to consider the overall eco-environment of the translation and select and transform the dimensions adaptively in order to achieve the final translation purpose, but also requires the translator to have the subjective initiative to carry out translation activities in the translation of the original text and under the restriction of the overall eco-environment of the translation. Only then can we display the ideological content of the original text as much as possible, express the feelings of the original author, and achieve the communicative purpose.

\section{References}

Chesterman, A. (2005). Towards consilience? In K. Aijmer and C. Alvstad (Eds.), New tendencies in translation studies (pp. 19-27). Goteborg: Goteborg University.

Hu, G. S. (2004). Translation adaptation and selection theory. Wuhan: Hubei Education Press.

Hu, G. S. (2008a). Translation theory from the perspective of terminology —an overview of translation adaptation and selection. Shanghai Journal of Translators, (2), 1-5.

Hu, G. S. (2008b). Interpretation of ecological translation studies. Chinese Translators Journal, (6), 11-15.

Hu, G. S. (2011). Eco-translatology: Research foci and theoretical tenets. Chinese Translators, (2), 5-9.

Lian, S. N. (2010). Contrastive studies of English and Chinese. Beijing: Higher Education Press.

Xu, Y. C. (2006). The art of translation. Beijing: Wuzhou Spreading Press. 